anales de psicología, 2012, vol. $28, \mathrm{n}^{\circ} 2$ (mayo), 350-357 http://dx.doi.org/10.6018/analesps.28.2.148761
(C) Copyright 2012: Servicio de Publicaciones de la Universidad de Murcia. Murcia (España) ISSN edición impresa: 0212-9728. ISSN edición web (http://revistas.um.es/analesps): 1695-2294

\title{
Migration and Health. The relationship between self-assessment of health and diagnosed morbidity in young adults
}

\author{
Sol Juárez
}

Centre for Economic Demography, Lund University (Lund, Sweden)

\begin{abstract}
Título: Inmigración y salud. La relación entre la salud autopercibida y las morbilidades diagnosticadas en adultos jóvenes.

Resumen: Los estudios procedentes de la salud pública y la epidemiología consideran a la salud percibida como un indicador de salud general, por su capacidad predictiva sobre la mortalidad. Evidencias empíricas en esta dirección han justificado el uso generalizado en las encuestas de salud y su aplicación por lo tanto a la población general. Sin embargo, es importante evaluar si es extensible a diferentes poblaciones y contextos. En la actualidad, existen estudios que confirman el mismo efecto en países menos desarrollados. No obstante, está lejos de ser exhaustivo y, lo más importante, todavía está pendiente explorar las diferencias culturales existentes en distintas poblaciones residiendo en un mismo contexto. El presente estudio precisamente trata de cubrir este vacío estudiando comparativamente dos aspectos concretos relacionados con esta medida de salud en la población española y extranjera residiendo en España. Por un lado, este estudio estudiará aspectos vinculados a la escala de medición de la respuesta sobre la percepción de la salud. Por otro lado, se evalúa el impacto y la composición de las morbilidades diagnosticadas que se asociadas a una mala percepción de la salud. Los datos proceden de la Encuesta de Salud de la Ciudad de Madrid 2005.
\end{abstract}

Palabras clave: salud autopercibida; encuesta; morbilidades; inmigrantes.

\section{Introduction}

The new age of international migrations, which started in the 1970s, has involved a change in the orientation of public policies towards the achievement of social integration and has produced the diversification of migration studies, which no longer show interest in the causes and motivations of the process, the main topics for decades, and have focused instead on other dimensions of the phenomenon, such as the relationship between immigration and education or immigration and employment. In this new context, exploring migrants' health allows both theoretical and practical advances, because health is, as education and employment, a dimension of social integration.

Spain has a relatively short history of immigration, however, this phenomenon has gone on to play an important role in the social and demographic experience of its population in recent years. This fact has been correlated with an increase in the number of studies focusing on different dimensions of this phenomenon and aspects that had not been previously addressed: migration and education (Aja et al., 2000; Palomares, 2006), migration and employment (Pajares, 2008; Cachón, 2009) migration and health (Jansà and Olalla, 2004; Vall-Llosera et al., 2009).

Studying immigrant's health is a big challenge for two main reasons. On the one hand, it is necessary to have recourse to databases that can perform the analysis providing

Dirección para correspondencia [Correspondence address]: Sol Juárez. Centre for Economic Demography, Lund University. P.O. Box 7083. S-22007 Lund (Sweden).E-mail: sol.juarez@ekh.lu.se
Abstract: Studies from the public health and epidemiologic fields consider self-assessment of health as a solid measure of general health due to its predictive ability in relation to mortality. Empirical evidence in this direction have justified the generalized use of this measure in health surveys as well as its application to the general population. However, it is important to evaluate whether these findings can be extended to different populations and contexts. Some studies have confirmed the existence of the same effect in some less developed countries but they are far from being exhaustive and it is still necessary to explore the possible cultural differences existing in diverse populations residing in a certain context. This study precisely contributes to fill this gap by exploring comparatively two specific aspects of self-assessment of health in both Spaniards and immigrants residing in Spain. On the one hand, the present research addresses a measurement aspect linked to the scale used to answer the question about self-assessment health, that is, the comparability of the answer as function of migratory status. On the other hand, this study evaluates the impact and composition of the morbidities associated to a poor self-assessment health. The data used for this study comes from the 2005 General Heath Care survey for the city of Madrid.

Key words: self-reported health; self-assessment health; surveys; morbidities; immigrants.

guarantees of population representativeness. And, on the other hand, it demands the use of cross-cultural health indicators, which involves using instruments which might be able to capture the same dimension of health in all groups of the population that it is applied to. Comparing health outcomes between immigrants and natives is essential in order to identify the specific necessities of the foreigner population. Therefore, it requires using comparable measures to assess health.

In Spain, none of the national's surveys available to date guarantees the statistical representativeness of the foreigner population. Moreover, the only source that can fulfil this requirement, the National Survey of Immigrants (2007) provided by the Spanish National Statistical Institute, does not consider either items of health nor allows the comparison with natives. In order to face this lack then, it is necessary to address the study focusing on specific geographic areas in order to have certain control of the existing heterogeneity. It is important to bear in mind that the profile of migrants varies in the whole national territory (Egea Jimenéz, Nieto Calmaestra et al., 2005; Simó Noguera, Méndez Martínez et al., 2007). Accordingly, this study has been focused on Madrid's latest health survey, which offers a great opportunity to compare to the health status of Spaniards and immigrants for a relatively large sample size.

Self-perception of health has been considered one of the most important measures in assessing general health in surveys. It consists in asking people to assess their health status from 'Poor' to 'Excellent' on a Likert scale. Self-perception of health, first in Maddox and Douglas's study in the 1970s, and increasingly from Mossey and Shapiro's study in 1982, 
has been understood as a predictor of survival. The exhaustive review by Idler and Benjamini (1997) finally systematized evidence on the matter by corroborating the effects of self-perception on mortality in 26 studies made in the United States. This finding offered enough empirical evidence to justify its presence in health questionnaires, and later revisions (Desalvo, Bloser et al., 2005) have kept on offering consistent results in this direction.

In spite of the fact that the link between health selfperception and subsequent mortality has been demonstrated to be very strong. However, this evidence has been observed predominantly in developed countries. Thus, although there is evidence that supports the same effect in some developing contexts (Zimmer et al., 2000; Frankenberg, and Jones, 2004) as well as its existing inverse gradient with respect to educational attainment (Subramanian et al., 2009), the casuistic to date which validates this measure as a predictor of survival is quite reduced. Moreover, other studies question this predictor capability. Thus, conversely, one study has validated this measure among Latinos in the United States, demonstrating that poor self-reported health was found to show a weaker predictor of subsequent mortality risk among the less acculturated (defining as those with less than 10 years residing in the host countries) (Finch et al., 2002).

In spite of the lack of a universal validation as a predictor of survival, self-reported health is extensively used in all those contexts were there are available health surveys that can provide this information. In these studies, self-reported health is considered a subjective evaluation of health that combines physical and emotional components, including a sense of wellbeing and satisfaction (Szwarcwald, 2005; Fylkeness and Helge, 1992). In this framework, its uses has been extended and defined as a global health indicator. Nevertheless, apart from this broad definition, there are still some aspects to be taken into account before using it to contrast populations. These aspects are related to the perception of the self-reported scale and its determinants.

This study will fill the gap by exploring these aspects and taking a cross-cultural approach with two objectives. The first aim is to evaluate the self-perception of health in both collectives separately. Previous studies have explored this aspect attending to differences related to the meaning of the self-reported health's categories or the cultural dimension that could influence a certain choice of response. Thus, for example, while 'Regular' in Spanish could mean 'Okay' or 'Fine' (but also 'So-so') whereas its equivalent in English, 'Fair', clearly implies a negative perception of health (Bzostek et al., 2007). Furthermore, it has been found that Hispanics, for instance, have been described as having a more pessimistic view of their health than other cultures (Angel and Guarnaccia 1989; Franzini and FernandezEsquer, 2004). Contrary to this view, the present study seeks to question this dimension by attending to its measurement implications. We expect that the variability existing between immigrants and natives will have an impact on the scale of health perception they have. In other words, self-reported health's scale is assumed to be an ordinal variable offering an equal distance within its categories. Accordingly, it is supposed that a change from, i.e. 'Good' to a 'Very good' category implies the same effort involved in a change from 'Poor' to 'Good'. Our first hypothesis is that migrants tend to polarize the scale, differentiating predominantly between 'poor' and 'Excellent' without showing a gradient between categories. Assessing this aspect is capital, since the lack of gradient could have important implications when using this variable as a response in an ordinal regression model, especially if the differences affect only one particular collective.

The second aim of this study is to explore whether the probability of reporting poor health is related to the same structure of morbidities among immigrants and natives, and if the state of mind which influences the probability of reporting a poor health outcome is the same in both collectives. This variable was introduced into the analysis in an attempt to capture more contextual information, not necessarily related to physical health but to social wellbeing. In other words, we are trying to the explore the different aspects included in the WHO's definition of health. i.e 'Health is a state of complete physical, mental and social well-being and not merely the absence of disease or infirmity' (Grad, 2002). In this regard, we expect migrants and Spaniards to be affected by a different set of morbidities and immigrants' poor health to be determined strongly by their state of mind rather than by their morbidities. This second aim will allow us to understand the structural components of perceiving poor health, which is mainly important for policy making.

\section{Methods}

\section{Participants}

The study was based on the General Health Care Survey developed by the Ayuntamiento de Madrid in 2005. The total sample size studied consisted of 5,661 interviews within 1665 years old. Immigrants were defined as individuals who were born in some country of the following geographic areas: East of Europe, Africa and Latin America. The sample is distributed by the migration variable as follows: $82.46 \%$ of Spaniards $(4,737)$ and $16.08 \%$ of immigrants $(924)$. Actually, one of the main limitations of our study is related to the design of the sample because it did not aim at making immigrant groups statistically representative, rendering impossible the desegregation of the sample by sub-groups of immigrants according to country of origin.

As it is observed in Table 1, the immigrant population resident in Madrid has a social and demographic structure significantly different from the Spanish one, even in the segment of population chosen for our study, which is economically active young adults. First, and consistently with their economically active role, immigrants are on average 6 years younger than Spaniards (mean $=36$ years old; $S D=10$ years in immigrants and mean $=41$ years old; $S D=14$ years in Spaniards). Thus, while $42 \%$ of the Spaniards were between 
45 and 65 , only $20 \%$ of the immigrants were in that age group, although in both collectives $80 \%$ of population was situated between 25 and 65. Second, in terms of the distribution of the maximum level of education achieved, there are statistically significant differences in favour of the Spanish population, referring mainly to the higher levels of education, graduate and post-graduate studies $(22 \%$ for immigrants and $33 \%$ for Spaniards). With respect to gender, the sample is balanced in both collectives (47\% males and 53\% female in Spaniards and $48 \%$ males and $52 \%$ female in immigrants).

Regarding self-perception of health, we have found that immigrants assess their health slightly (which is, nonetheless, statistically significant) more positively than Spaniards. Immigrants reporting 'Good health' surpassed Spaniards in the same category by $3 \%$.

Regarding diagnosed morbidities or objective measures of health, it is important to underline that there are statistically significant differences in the prevalence of some morbidities, such as cardiovascular and endocrinal, psychological, musculoskeletal and respiratory morbidities, but these differences are very influenced by age and, as we have mentioned, have a different structure.

Table 1. Descriptive Statistics of variables in the models.

\begin{tabular}{|c|c|c|c|c|}
\hline & \multirow[b]{2}{*}{ Inmigrants (\%) } & \multirow[b]{2}{*}{ Spaniards (\%) } & \multicolumn{2}{|c|}{ Pearson's X2 Test } \\
\hline & & & Chi-Square & Sig. \\
\hline Place of Birth & 841 & 4,866 & & \\
\hline Age & & & 165.33 & 0.000 \\
\hline $16-24$ & 13.79 & 14.24 & & \\
\hline $25-44$ & 65.76 & 43.36 & & \\
\hline 45-65 & 20.45 & 42.40 & & \\
\hline & (841) & $(4,866)$ & & \\
\hline Gender & & & 0.742 & 0.389 \\
\hline Male & 48.26 & 46.67 & & \\
\hline Female & $\begin{array}{l}41.72 \\
(841)\end{array}$ & 53.33 & & \\
\hline Education & (841) & & 41.48 & 0.000 \\
\hline Illiterate & 5.14 & 4.17 & & \\
\hline Primary & 33.17 & 26.20 & & \\
\hline Secondary & 39.52 & 36.81 & & \\
\hline Post-graduate & 22.16 & 32.80 & & \\
\hline & (835) & $(4,857)$ & & \\
\hline Self-perception of health & & & 58.02 & 0.055 \\
\hline Good & 85.70 & 82.59 & & \\
\hline Poor & 14.30 & 17.41 & & \\
\hline & (839) & $(4,853)$ & & \\
\hline Perception of happiness & & & 64.62 & 0.091 \\
\hline Much happier than usual & 9.10 & 6.83 & & \\
\hline Happier than usual & 27.90 & 28.26 & & \\
\hline Not happier than usual & 91.72 & 63.36 & & \\
\hline Not at all happy & 1.08 & 1.55 & & \\
\hline & (835) & $(4,774)$ & & \\
\hline Morbidities & & & & \\
\hline Cardiovascular and endocrinologycal pathologies & 31.27 & 27.62 & 4.73 & 0.030 \\
\hline Psychological distress & 6.42 & 8.47 & 4.00 & 0.045 \\
\hline Musculoskeletal & 5.83 & 4.86 & 50.00 & 0.000 \\
\hline Digestive and gastrointestinal & 9.51 & 9.23 & 0.70 & 0.762 \\
\hline Eye and ear & 1.55 & 1.66 & 0.06 & 0.803 \\
\hline Urinary & 0.83 & 0.39 & 3.09 & 0.079 \\
\hline Respiratory system & 12.01 & 16.52 & 10.95 & 0.001 \\
\hline
\end{tabular}

\section{Instrument}

Self-perception of health is our dependent variable, which is originally categorized on a Likert scale with 5 items: 1-'Bad', 2-'Fair', 3 -'Good', 4 -'Very good', 5- 'Excellent'. We have kept this variable as ordinal to fit the categorical regression with optimal scaling and for logistic regression it was re-coded as a binary outcome: 1-'Fair/Bad' and 0'Good/Very good/Excellent'.

The control variables selected were gender, age re-coded into three categories (16-24, 25-44, 45-65) and education into four categories (1-'Illiterate', 2-'Primary level', 3'Secondary level' and 4- 'Third grade'.

The explanatory variables are the morbidity measures, which have been obtained from a question of the questionnaire ('could you tell me if your doctor has told you whether you suffer from any of the conditions that I will mention?') and they have been categorized for this study into eight groups: cardiovascular and endocrinological pathologies (circulatory problems, hypertension, cholesterol, diabetes, angina pectoris and other heart diseases, cardiovascular accidents, varicose veins, uric acid, thyroids), musculoskeletal (arthrosis, arthritis and rheumatism, fibromyalgia, osteoporosis, disc hernia and lumbalgia), digestive and gastrointestinal (stomach problems, constipation and hepatitis), urinary (prostate and kidney problems), psychological distress (anxiety, depression and schizophrenia), ear and eye affections (cataract, glaucoma and deafness) and respiratory system (asthma, allergy and apnoea). These variables were introduced into the model as ordinary variables (the number of morbidities of this group a person experiences) and they were standardized to allow comparison between models. The explanatory variable reporting the state of mind asked whether a person was feeling reasonably happy considering her/his circumstances and it was coded on a scale of 4 items 1- 'More than usual', 2- 'Slightly more than usual', 3- 'Not more than usual', 4- 'Not at all' and we re-coded into 1'More than usual' 2- 'No more than usual', 3- 'Not at all'.

\section{Procedure}

The interviews were carried out at the individual's home, after a prior communication by letter. The interviewers were chosen from the 'list of inhabitants' (Padrón de habitantes) with reference to $1^{\text {st }}$ September of 2004. The stratification criterion was based on district (21 strata) and the allocation of these districts was uniformed in an attempt to obtain information representative at this level of disaggregation. In each district it has been stratified by gender and sex attending to the structure of these variables in the territory. The duration was about 35 minutes for adults. The language of the interviews was Spanish.

\section{Data analysis}

Two types of analyses have been undertaken in this study to answer each of our research questions. First, Categorical regression analysis (CATREG) with optimal scaling was used to evaluate the differences between Spaniards and immigrants related to the scale in which they assess their health. The objective of this technique is to explain a response variable (perception of health, in our case) as a function of some explicative variables (gender, age and educa- 
tion, in our case). The optimal scaling technique of categorical data computes the numerical quantification of each of the response variables' ordinal categories, through an iterative method named 'alternating minimal square' that finds the best metric properties to describe the relationship between the response and the predictive variables. This technique is particularly useful to test (when using an ordinal response variable) whether the ordered categories are equidistant or there is a systematic pattern of variability according to other covariates, beyond the uncertainty due to measurement errors. Two models were fitted for Spaniards and immigrants including the same explanatory variables and their outcome provides the actual distance between the 'Excellent', 'Very good', 'Good', 'Fair' and 'Poor' categories, taking into account a number of explanatory variables - sex, gender, education, morbidities and state of mind -. Second, a logistic regression was used to assess the impact of the morbidities and state of mind on the prediction of a poor perception of health. Two models were run for Spaniards and immigrants using as a binary response variable reporting poor health, controlled by age, gender and education.

\section{Results}

\section{Exploring differences in the conceptualization of the scale}

Table 2. offers the results of the categorical regression analysis with optimal scaling, showing that the response categories for the perception of health have a completely different distribution depending on whether the interviewee was native or immigrant: Spaniards assess their health in a gradual, incremental tendency, which only blurs between the last two categories ('Very good' and 'Excellent') whereas immigrants do not differentiate among the categories in the margins ('Excellent'-'Very good' and 'Fair'-'Poor') but find a clear distance between them and the central category 'Good'.

The positive categories ('Good', 'Very good' and 'Excellent') tend to converge in both collectives, although there is an important distance between the negative categories ('Fair' and 'Poor') (see figure 1). Where immigrants report lower levels of poor health $(-2.35)$, they need to make a greater effort to attain the 'Good' category. This means that to jump from 'Fair' to 'Good' involves 1.75 points of distance for Spaniards and 2.42 for immigrants.

This result - that immigrants do not show a lineal relationship between the categories as Spaniards do - justifies the methodology used in the next heading, a logistic regression that assesses the impact of morbidities and the state of mind they are in over reporting poor health, which is the category where more differences have been found.
Table 2. Category quantification of response variable: Self-perception health.

\begin{tabular}{lllll}
\hline & \multicolumn{2}{c}{ Immigrants } & \multicolumn{2}{c}{ Spaniards } \\
\cline { 2 - 5 } \multicolumn{1}{c}{ Categories } & Frequency & Quantification & Frequency & Quantification \\
\hline Poor & 8 & -2.351 & 117 & -3.766 \\
Fair & 116 & -2.351 & 677 & -1.655 \\
Good & 440 & 0.075 & 2322 & 0.094 \\
Very Good & 267 & 0.720 & 1284 & 0.827 \\
Excellent & 64 & 1.035 & 288 & 0.977 \\
\hline Number of observations & 895 & & 4688 & \\
Prob>Chi2 & 0.000 & & 0.000 & \\
Pseudo R2 & 0.15 & & 0.27 & \\
\hline
\end{tabular}

Note: Quantifications obtained after controlling for education, gender, age, cardiovascular and endocrinologycal pathologies, psychological distress, musculoskeletal, digestive and gastrointestinal, eye and ear, urinary and respiratory system.

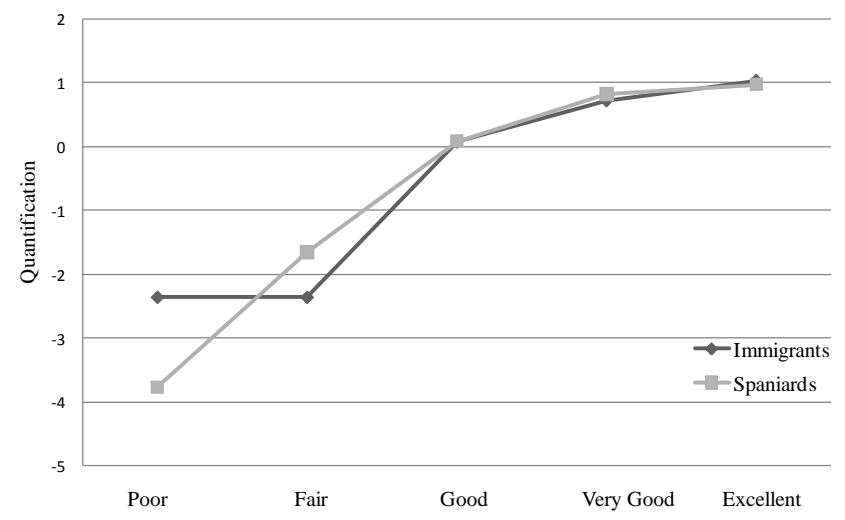

Figure 1. Quantifications of self-perception of health compared between immigrants and Spaniards.

\section{Exploring the differential structure of reported health in both populations}

The second aim of this study is to explore the health variables related to a poor self-perception of health. Table 3. Presents the odds ratios associated with each variable. The models show a different structure depending on whether the interviewee was Spanish or immigrant, which can be observed in the number of significant variables in both models. The morbidities that produced the highest odds of reporting a poor health condition among immigrants were the digestive and gastrointestinal and musculoskeletal ones. These were controlled by gender, age and educational variables. For Spaniards, the only variable not statically significant was that related to respiratory morbidities. Surprisingly, none of the collectives show a predominant effect of the group of cardio-vascular morbidity on perception of health when it is the first cause of chronic affection in both groups $31 \%$ of prevalence for immigrants and $28 \%$ for natives).

For each additional digestive and gastrointestinal morbidity suffered, the odds of reporting a poor perception of health rose to 1.48 for immigrants, while 1.25 for the Spaniards. Conversely, the odds are incremented in 1.51 with each new musculoskeletal morbidity suffered by the host population in comparison to 1.43 in the case of immigrants. The odds of reporting a perception of poor health among Spaniards are related mainly to the possibility of suffering a 
musculoskeletal or a psychological morbidity and, to a lesser extent, cardiovascular and endocrinologycal pathologies (OR:1.28), digestive and gastrointestinal (OR:1.25), urinary morbidities (OR:1.11) and of the senses (OR:1.10).

In spite of the differences between the number and degree of impact of the morbidities affecting the probability of reporting poor health as perceived by the group of Spaniards on the one hand, and of immigrants on the other, there are also similarities. Musculoskeletal morbidity is one of the most important for both groups; it is the second in order of prevalence among Spaniards $(15 \%)$ and the fifth among immigrants $(5.83 \%)$ with statistically significant differences for both collectives. According to this, we could find a common pattern among the objective measures of health introduced in the model.

The state of mind variable has shown an important relationship on the odds of reporting poor health (OR:1.27 at the limit of the signification for the immigrant population and clearly significant for Spaniards, OR:1.16).

Table 3. Results of logistic regression models for self-reported health and objective and subjective measures of health among immigrant and Spanish populations (odds ratios).

\begin{tabular}{|c|c|c|c|c|c|c|c|c|}
\hline \multirow[b]{2}{*}{ Self-perception: poor health } & \multicolumn{3}{|c|}{ Immigrants } & \multicolumn{5}{|c|}{ Spaniards } \\
\hline & OR & Std. Err. & Wald & IC-95\% & OR & IC-95\% & Std. Err. & Wald \\
\hline \multicolumn{9}{|l|}{ Morbidities } \\
\hline Psychological distress & 1.048 & .120025 & 0.41 & {$[0.837-1.312]$} & $1.514 * * *$ & {$[1.415-1.620]$} & .0524125 & 11.99 \\
\hline Cardiovascular and endocrinologycal & 1114 & 1013330 & 110 & ] & $1282 * * *$ & {$\left[\begin{array}{lll}1 & 184 & 1888\end{array}\right]$} & $051900 ?$ & 613 \\
\hline $\begin{array}{l}\text { pathologies } \\
\text { Musculoskeletal }\end{array}$ & $\begin{array}{l}1.114 \\
1.428 * *\end{array}$ & $\begin{array}{l}.1013339 \\
.190826\end{array}$ & $\begin{array}{l}1.19 \\
2.66\end{array}$ & {$[1.098-1.855]$} & $1.282 * * *$ & {$[1.413-1.624]$} & .0519992 & $\begin{array}{l}0.13 \\
11.70\end{array}$ \\
\hline Digestive and gastrointestinal & $1.481 * * *$ & .1324908 & 4.39 & {$[1.243-1.765]$} & $1.254 * * *$ & {$[1.160-1.354]$} & .0495122 & 5.72 \\
\hline Eye and ear & 0.883 & .1267296 & -0.87 & {$[0.666-1.170]$} & $1.095 *$ & {$[1.021-1.174]$} & .0391866 & 2.53 \\
\hline Urinary & 1.079 & .063166 & 1.30 & {$[0.962-1.210]$} & $1.113 * *$ & [1.044-1.186] & .0361446 & 3.28 \\
\hline Respiratory system & 1.150 & .1275747 & 1.26 & [0.926-1.430] & 1.064 & {$[0.977-1.160]$} & .0466207 & 1.42 \\
\hline State of mind & $1.268^{*}$ & .1453534 & 2.07 & [1.013-1.587] & $1.163 * *$ & [1.060-1.277] & .0551806 & 3.19 \\
\hline \multicolumn{9}{|l|}{ Gender } \\
\hline \multicolumn{9}{|l|}{ Male (ref.) } \\
\hline Female & $1.627^{*}$ & .3685323 & 2.15 & [1.044-2.536] & 0.904 & {$[0.755-1.083]$} & .0832984 & -1.09 \\
\hline \multicolumn{9}{|l|}{ Age } \\
\hline \multicolumn{9}{|l|}{$16-24$ (ref.) } \\
\hline $25-44$ & 1.802 & .694903 & 1.53 & [0.847-3.837] & $1.783 * *$ & {$[1.248-2.548]$} & .3248709 & 3.17 \\
\hline $45-65$ & 2.306 & 1.010 .073 & 1.91 & {$[0.978-5.441]$} & $2.547 * * *$ & {$[1.779-3.647]$} & .4663146 & 5.11 \\
\hline \multicolumn{9}{|l|}{ Education } \\
\hline \multicolumn{9}{|l|}{ Post-graduate (Ref.) } \\
\hline Secondary & $1.975^{*}$ & .6643387 & 2.02 & {$[1.021-3.818]$} & $1.764 * * *$ & [1.389-2.240] & .2152039 & 4.65 \\
\hline Primary & $2.564 * *$ & .8600237 & 2.81 & [1.328-4.948] & $2.589 * * *$ & {$[2.043-3.282]$} & .3133392 & 7.86 \\
\hline Illiterate & $3.670 * *$ & 1.725 .802 & 2.77 & {$[1.461-9.225]$} & $4.952 * * *$ & {$[3.326-7.375]$} & 1.006 .093 & 7.88 \\
\hline Number of observations & 812 & & & & 4688 & & & \\
\hline Prob $>$ Chi2 & 0.0000 & & & & 0.0000 & & & \\
\hline Pseudo R2 & 0.12 & & & & 0.21 & & & \\
\hline Porcentage of correct classification & 86.46 & & & & 85.30 & & & \\
\hline
\end{tabular}

Note: ${ }^{*} p<0.05 ; * * p<.01 ; * * * p<.001$

It is important to note that a full model including immigration as an additional explanatory variable was run with non-significant results. This means that there are no statistical differences in the negative assessment of health related to being immigrant or Spanish. Statistical differences are, as we have seen, linked to experiencing morbidities, a feeling of happiness.

The control variables included in the analysis (age, gender and education) are in the expected direction. Only age is not statistically significant for immigrants but for Spaniards.

In other words, there are no differences assuming constant structure and combination of effects, which produces a single coefficient to measure the effect of each one. The interest of our research, however, was to explore the differential structure and the specific effects of the explicative variables in each collective, especially as we have already distinguished different perceptions of the scale.

\section{Discussion}

Contrary to other studies (Dunn and Dyck 2000; Bzostek et al., 2007), ours shows that immigrants declare a negative perception of their health in a smaller proportion (14\%) than Spaniards (17\%). These results fit the Epidemiologic Paradox 
hypothesis that states that immigrants have similar -or better- health outcomes than natives (Teller and Clyburn 1974; Gutmann et al., 1998; Jasso et al. 2004; Wingate et al., 2006; Hummer et al., 2007). At the same time, finding a poorer health perception in the populations of post-industrial societies could be the consequence of a higher use of medical services in those societies. As a classic example we could cite the unquestionably better levels of health enjoyed since the 70 s and 80 s in the United States coexisting with a systematically worse perception of health (Henriques, 1995).

The first aim of this study was to explore the possibility that immigrants perceived the scale of health in a different way than Spaniards. We found that immigrants tend to cluster the category of 'Poor' /'Fair' and 'Very good' / 'Excellent' while Spaniards spread their answer over a wide range of categories. This finding is consistent with other studies focused on the self-perception of health in developing countries (Frankenberg and Jones, 2004).

The results observed lead to the need of addressing the factors behind those differences. Here, the cultural dimension undoubtedly acquires an important explanatory role as the expression of well-being is always culturally mediated. In this sense, comparing health status without taking that into account could lead to a significant epistemological fallacy. For example, the growing medicalization process along with the increasing use of health services (assistential factor) that characterizes post-industrial societies could be partly behind the differences we find in the data. It is plausible that people socialized in such a context could develop a higher medical consciousness, being more sensitive to discriminate between the different categories of health. Unfortunately, our data did not allow us to explore this aspect further, but it needs to be considered as an important aspect for future research. However, in spite of the importance of this finding for further work in the field, the fact that immigrants tend to polarize their answer has already important measurement implications. Thus, the fact that immigrants do not show a linear relationship between the categories - as Spaniards do- justifies the methodology used to answer the second research question (logistic regression).

The second aim of this study was to explore whether the probability of reporting poor health is related to the same structure of morbidities among immigrants and natives, and if the relative influence of the individual's state of mind on the probability of reporting poor health is the same between these collectives. Our finding shows that regardless of origin, reporting poor health is related to the presence of some groups of morbidities such as musculoskeletal, digestive and gastrointestinal, as each additional morbidity increases the odds of assessing health status as poor. However, with the only exception of the respiratory group, all morbidities have a statistical relationship with the odds of reporting poor health in Spaniards.

It is possible that musculoskeletal morbidities are hiding different types of affections in each collective. Thus, while among Spaniards it could be related to chronic diseases as- sociated with age, for immigrants it could be related to the type of work undertaken (for example lumbalgia or arthritis). In fact, it has been observed that a high percentage of the interviewed immigrants were employed in manual labour $(22 \%$ in immigrants and 9\% in Spanish).

The next morbidity that affects negative perception of health in both collectives is the digestive and gastrointestinal group. Here we have to consider the tendency towards somatic behaviour in some groups of origin, such as the case of Hispanics living in United States and in other developing societies (Angel and Guarnaccia, 1989). It is reasonable to ponder whether this fact could be pointing up a hidden relationship between digestive and psychological problems in our interviewees, this possibility being widely supported by the literature (Lee et al. 2000; Haug et al., 2002).

'State of mind' is a measure difficult to define, but its significant impact on self-perception is evidence supporting the notion that perception of health is a complex measure that includes physical and emotional dimensions. General health forces us away from the traditional confrontation of health as the correct functioning of systems (objective health) and health understood in terms of general well-being (subjective health). For some scholars, this is nothing more than the encounter between medical evaluation, based on the separation and dislocation of diagnosed problems that are anatomically localized and affect a particular system of organs, and health as it is experienced by individuals, as a global function of experience and well-being (Barsky et al., 1992).

At the same time, it is conceivable that many other aspects of well-being related to other dimensions of life (emotional or affective, for example) could be captured under medical jurisdiction. Furthermore, the contribution of the variable 'state of mind' to the odds of reporting poor health could be lower among Spaniards as a consequence of their higher tendency to discern between physical and emotional effects. In the same way, the higher impact of psychological morbidities (along with a higher probability of being diagnosed) could be a consequence of naming practices, understanding and also treating worries and concerns in medical terms, or, in other words, 'medicalizing' them ${ }^{1}$ (Conrad, 1992).

Finally, we should not forget the temporal perspective of the migratory status and its cultural specificities. The differences found in this research could be temporary as inserted in the integration process of immigrants in their host country. The generational migration status could then have an important role in the future of these studies.

Self-perception of health in an adult population has shown a relationship with objective health measures, although the structure of morbidities that affect Spaniards and immigrants and the different interpretation of the scale of

1 There are many examples of these processes, among which we can mention anorexia, homosexuality, drug consumptions, menopause, or ageing (see more details in Conrad, 1992). 
health should not be isolated from the social and cultural context that surrounds the individuals under study. The increase in social benefits and the ongoing medicalization process in post-industrial societies, which is a consequence of the combined effects of secularization and changes in medical organization, promoted by technical advances and specialization, are responsible of the social construction of health perceptions. For these reasons, although selfperception of health could be defended as the best instrument to capture the modern definition of health ${ }^{2}$, the factors involved on it are less inclusive in post-industrial societies. As our data shows, the state of mind of Spaniards has a lower impact in perception of health than that of immigrants.

The control variables included in this analysis (age, gender and education) have been identified as working in the direction already noted in the literature. Thus, the odds of reporting poor health increase as the educational level decreases (Furneé et al., 2008; Subramanian, 2010), age rises (Eriksson et al., 2001; Asfar et al., 2007) and it is more likely among women than men (Eriksson et al., 2001).

To conclude, we would like to dwell on the main limitation of this study, namely the definition of the concept 'immigrant'. The immigrant population residing in Spain is a very heterogeneous group owing to the large number of countries of origin. In fact, multiculturalism is one of the key features of the Mediterranean host countries as opposed to

\section{References}

Aja, E., F., Carbonell, F; Colectivo Ioé ; Funes, J and Vila, I (2000). La Inmigración extranjera en España. Los retos educativos. La inmigración extranjera en España. Los retos educativos. C. d. E. Sociales. Barcelona, Funcación La Caixa. 1-125.

Asfar, T., B. Ahmad, B., Rastam, S., Mulloli, T. P., Ward, K.D and Maziak, W (2007). Self-rated health and its determinants among adults in Syria: a model from the Middle East. BMC Public Health, 7, 177.

Angel, R. and P. J. Guarnaccia (1989). Mind, Body, and Culture: Somatization among Hispanics. Social Science and Medicine, 12, 1229-1238.

Arango, J. (2002). La Fisionomía de la Inmigración en España. Red Internacional de Migración y Desarrollo 1-16.

Barsky, A. J., P. D. Clearly, P.D and Klerman, G.L. (1992). Determinants of Perceived Health Status of Medical Outpatients. Social Science and Medicine, 10, 1147-11554

Bzostek, S., Goldman, N., Pebley, A (2007). Why do Hispanics in the USA Report Poor Health? Social Science and Medicine, 65, 990-1003

Cachón Rodríguez, L. (2009). La España inmigrante: marco discriminatorio, mercado de trabajo y políticas de integración. Barcelona, Anthropos.

Conrad, P. (1992). Medicalization and social control. Annual Review of Sociology 18: 209-232.

Desalvo, K. B., Bloser, N., Reynolds, K., He, J., Muntner, P (2005). Mortality Prediction with a Single General Self-Rated Health Question. A Meta-Analysis. Journal of General Internal Medicine, 20, 267-275.

Dunn, J. and I. Dyck (2000). Social Determinants of Health in Canada's Immigrant Population: Results From the National Population Health Survey. Social Science and Medicine, 51, 1573-1593.

Egea Jiménez, C., Nieto Calmaestra, J.A., Rodríguez Rodríguez, V., Jimenéz Bautista, F. (2005) La inmigración actual en Andalucía (1997-2001). Scripta Nova, 192,741-98.

Eriksson, I., Undén, A.L; 1 and Elofson, S (2001). Self-Rated Health. other European countries experiencing immigration processes (Arango, 2002).

The smallness of the sample size did not grant us the possibility of a more thorough analysis, however, this study could be considered as an exploratory analysis encouraging further inquiry in the field.

We consider that the results of this type of study are not fixed on time since immigrants could change their perception of health over the period of residence in the host society. Unfortunately, the dataset does not allow us to distinguish more than those with more/less than five years' residence, while the literature generally suggests at least ten years to start observing changes (Finch et al., 2002; McDonald, 2004).

Acknowledgments: The present paper has been made possible by a collaboration with Instituto Municipal de Salud Pública del Ayuntamiento de Madrid (Spain) and, especially, with the support of José Manuel Díaz Olalla. This research was undertaken thanks to the I3P grant held by Sol Juárez and the economic support from the project Mortality in Institutions in the framework of Urban Mortality: Madrid in an international comparative (SEJ2005-06334). At the same time, this study is part of the activity of two research groups: Grupo de Estudios de Población y Sociedad (GEPS) and Grupo de Investigación en Dinámicas Demográficas (GDD). I would like to acknowlege the suggestions and comments on earlier drafts of this paper by Dr. David Reher, Dr. Diego Ramiro Fariñas, Dr. Frans Van Poppel and Dr. Bárbara Revuelta Eugercios.

Comparisons Between Three Different Measures. Results From A Population Study. International Journal of Epidemiology, 30, 326-333.

Finch, B. K., Hummer, R.A., Reindl, M and Vega, W (2002). Validity of selfrated health among latino(a)s. American Journal of Epidemiology, 155, 755759 .

Frankenberg, E. y N. R. Jones (2004). Self-relared health and mortality: Does the relationship extend to a low income setting? Journal of Health and Social Behavior, 45, 441-452.

Franzini, L. and M. E. Fernandez-Esquer (2004). Socioeconomic, Cultural, and Personal Influences on Health Outcomes on Low Income Mexican-origin Individuals in Texas. Social Science and Medicine, 59, 1629-1646.

Furnée, C., Groot, W., (2008) and Van den Brink, H.M. The health effects of education: a meta-analysis. European Journal of Public Health, 18, $417-$ 21.

Fylkesnes, K. and O. H. Forde (1992). Determinants and Dimension Involved in Self-Evaluation of Health. Social Science and Medicine, 35, 271179.

Grad, F. (2002). Preamble to the Constitution of the World Health Organization as adopted by the International Health Conference. Bulletin of the World Health Organization, 80, 981-981.

Gutmann, M. P., Frisbie, P.W., DeTurk, P and Blanchard, S.K (1998). Dating the Origins of the Epidemiologic Paradox Among Mexican Americans. Washington: 1-25

Haug, T., Mykletun, A and Dahl, A (2002). Are Anxiety and Depression Related to Gastrointestinal Syntoms in the General Population? Scandinavian Journal of Gastroenterology, 294-298.

Henriques, A. (1995). La medicina social y la salud pública ante los desafíos del siglo XXI. Revista Cubana de Salud Pública, 21, 10-12.

Hummer, R. A., D. A. Power, et al. (2007). Paradox Found (again): Infant Mortality Among the Mexican-Origin Population in the United States. Demography, 44, 441-457. 
Idler, E. L. and Y. Benyamini (1997). Self-Rated health and mortality: A review of twenty-seven community. Journal of Health and Social Behavior, 38, 21-37.

Jansà, J. M. and Olalla García, P (2004). Salud e inmigración; nuevas realidades y nuevos retos. Gaceta Sanitaria 18, 207-213

Jasso, G., D. S. Massey, D.S., Rosenzweig, M.R and Smith, J.P et al. (2004). Immigrant Health: Selectivity and Acculturation. Critical Perspectives on Racial and Ethnic Differences in Health in Late Life. N. B. Anderson, R. A. Bulatao and B. Cohen. Washington D.C, The National Academies Press.

Lee, S., Park, M., Choi, S., Nah, Y., Abbey, S.E and Rodin, G (2000). Stress, Coping, and Depression in Non-Ulcer Dyspepsia Patients. Journal of Psychocomatic Research, 59, 93-99.

McDonald, T. J. and S. Kennedy (2004). Insight into the "healthy inmigrant effect": health status and health service use of inmigrant to Canada. $\underline{S}$ ocial Science and Medicine, 59, 1613-1627.

Mossey, J. M. y E. Shapiro (1982). Self-Rated Helath: a Predictor of Mortality Among Elderly. American Journal of Public Health, 72, 800-808.

Simó Noguera, C., S. Méndez Martínez, et al. (2007). El envejecimiento de la población extranjera en la Comunidad Valenciana y su imapcto en el sistema de salud. Gaceta Sanitaria, 29, 525-526

Pajares, M. (2008). Inmigración y mercado de trabajo. Informe 2007. Análisis de datos de España y Cataluña, Observatorio Permanente de la Inmigración.
Palomares Ruiz, A (2006). Educación e inmigración en España. Revista Española de Educación Comparada, 12, 339-364

Subramanian, S. V., A. Malavika., Selvarajb, S and Kawachia, I. (2009). Are self-reports of health and morbidities in developing countries misleading? Evidence from India Social Science and Medicine, 68, 260-265.

Subramanian, S. V., Huijts, T and Avendano, M (2010). Self-reported health assessments in the 2002 World Health Survey: how do they correlate with education? Bulletin of the World Health Organization, 88, 131-138.

Szwarcwald, C. L., P. Borges de Souza-Júnior., Pires Esteves, M., Nogueira Damacena, G and Viacava, F (2005). Socio-Demographic Determinants of Self-Rated Health in Brazil. Artigo, 21, 54-64.

Teller, C. H. and S. Clyburn (1974). Trends in infant mortality. Texas Business Review, 29, 97-108.

Vall-Llosera Casanovas, L., C. Saurina Canals and Saez Zafra, M (2009). Inmigración y salud: necesidades y utilización de los servicios de atención primaria por parte de la población inmigrante en la región sanitaria Girona. Revisión Española de Salud Publica, 83, 291-307.

Wingate, M., S. Alexander, et al. (2006). The Healthy Migrant Theory: Variation in pregnancy outcomes among US-born migrants. Social Science and Medicine, 62, 491-498.

Zimmer, Z., J. Natividad, et al. (2000). A cross-national examination of the determinants of self-assessed health. Journal of Health and Social Behavior, 4, 465-481.

(Article received: 09-12-2010, reviewed: 19-07-2011, accepted: 28-08-2011) 